\title{
High altitude pulmonary oedema: still a place for controversy?
}

High altitude pulmonary oedema (HAPE) is defined as acute respiratory failure following exposure to high altitude hypoxia, developing in a normal subject with no preexisting pulmonary or cardiac disease. It is one of the manifestations of high altitude disease of which the simplest form is acute mountain sickness (AMS), generally limited to headache, nausea and insomnia during the first few days spent above $2500 \mathrm{~m} .{ }^{12}$ In contrast to AMS, HAPE necessitates emergency management. It occurs 6-48 hours after rapid ascent to altitudes above $2500-4000 \mathrm{~m}$. Severe exercise and cold exposure favour its occurrence. Subjects complain of shortness of breath disproportionate to the effort exerted, a dry followed by a productive cough, fatigue, and chest pain. Clinical examination reveals tachypnoea, tachycardia, mild fever, cyanosis, crepitant rales and rhonchi. ${ }^{3-5}$ The heart rate is generally more than 120 beats/min and the respiratory rate more than 20 breaths/ min. There is no evidence of cardiac failure. When hospital facilities are available, radiographic examination shows diffuse infiltrates in two thirds of cases ("patchy distribution"), and prominence of pulmonary arteries. ${ }^{6}$ Patchy distribution is seen on chest radiography early in the disease, becoming bilateral and diffuse in the more advanced state. ${ }^{7}$ Clearing of these exudates lags a day or two behind clinical improvement. ${ }^{58}$ Electrocardiography shows tachycardia and signs of acute right ventricular overload. Doppler echocardiography may reveal tricuspid regurgitation or even tricuspid insufficiency. ${ }^{5}$ Haemodynamic parameters include a high pulmonary arterial pressure and low capillary wedge pressure. A mild leucocytosis may be found (rarely more than $14000 / \mathrm{mm}^{3}$ ). ${ }^{8}$ The arterial oxygen saturation $\left(\mathrm{SaO}_{2}\right)$ ranges from $40 \%$ to $70 \%, 910$ and vital capacity and peak expiratory flow are decreased. ${ }^{5}$ Neurological signs are frequently associated with HAPE and can dominate the clinical picture with incapacitating headache, staggering gait, ataxia, projectile vomiting, emotional lability, diplopia, dislocation in time and place, coma, and death. ${ }^{11}$ The mortality rate varies between $4 \%{ }^{12}$ and $11 \%,,^{13}$ depending on the rapidity of descent or oxygen treatment. The main differential diagnoses are pneumonia, pulmonary embolism, and left heart failure. In a Colombian study of 13 cases of HAPE the initial diagnosis was bronchopneumonia in children and myocarditis or coronary insufficiency in adults. ${ }^{8}$ Excessive speed of ascent is a major contributing factor to HAPE. In a group of 166 cases $65 \%$ took less than two days to reach the altitude at which they developed HAPE, and HAPE occurred before the fifth day in $73 \%$ of cases. Mortality was higher in subjects treated by descent alone $(12 \%)$ than in those treated with oxygen alone $(5 \%)$, or both $(3 \%)$; those not treated had a mortality rate of $44 \% .^{13}$

\section{Who can suffer from HAPE?}

The risk of developing altitude sickness occurs in many human activities including climbing, trekking, skiing, touring, and working at high altitude. HAPE can occur in people residing at high altitude (in the Andean Altiplano and in Colorado) who return from a few days' stay at a lower altitude ("re-entry" oedema). ${ }^{14} 15$ The incidence was $0.6 \%$ in adults and $8-9 \%$ in children in Peru in the $1970 \mathrm{~s}^{15}$
Mountaineers climbing high peaks in the Himalayas, the Andes, and also in Europe (Mont-Blanc, Monte Rosa), North America (Colorado, Alaska), and Africa (Mount Kenya, Kilimanjaro) are prone to develop HAPE, especially when they do not take enough time to acclimatise themselves to the altitudes between 2500 and $4500 \mathrm{~m} \cdot{ }^{13} \mathrm{~A}$ typical example is an alpinist arriving at a base camp around $5000 \mathrm{~m}$, excited by the idea of climbing the mountain, going up to a high altitude camp, expending a lot of energy, feeling tired and dyspnoeic, and found dead the next morning in his tent.

Cases are often observed in less severe conditions such as ski resorts in the $\mathrm{Alps}^{1617}$ and Colorado, ${ }^{18}$ or trekking in Nepal (Everest base camp, tour of Annapurna). ${ }^{1}$ The small number of cases in Europe is explained by less information about HAPE, the short duration of stay, and a relatively easy descent. A new group susceptible to HAPE are sedentary and elderly people touring places of cultural interest such as Lhasa in Tibet $(3500 \mathrm{~m})$ or $\mathrm{La} \mathrm{Paz}$ in Bolivia (3500-4000 m).

Soldiers fighting in high regions are at great risk. For example, the Sino-Indian war at the beginning of the 1960s caused a large number of casualties from high altitude diseases among the Indian troops (not acclimatised) but not the Chinese, and promoted a series of studies by Indian physicians. ${ }^{1219-21}$ Even today a war is being conducted between India and Pakistan on a contested border at $5000-6000 \mathrm{~m}$ with many casualties from high altitude disease.

Human activities at high altitude, such as astronomers at observatories in Mauna Kea, Hawaii (4200 m) or miners in Peru, Bolivia or North Chile (up to $5950 \mathrm{~m}$ ) raise the question of detecting susceptible subjects and its significance in occupational medicine. Thousands of workers, resident at sea level, will work in newly developed Chilean mines over the next few years, spending one week working at around $4500 \mathrm{~m}$ and one week resting at low altitude. This is a new challenge for physicians involved in the selection and follow up of this population.

\section{Who "discovered" HAPE?}

AMS was first described in ancient texts from Asia and then by explorers in South America. ${ }^{2223}$ The first scientific studies on AMS began in Europe in the 18th century, and became more extensive in the 19th century with the work of Paul Bert ${ }^{24}$ and the development of high altitude laboratories by Joseph Vallot on Mont Blanc ${ }^{225}$ and Angelo Mosso on Monte Rosa. ${ }^{26} \mathrm{Dr}$ Jacottet died in the Vallot Observatory at the top of Mont Blanc in 1891 from acute respiratory distress; the necropsy revealed a normal heart and lungs with bilateral congestion and considerable oedema. ${ }^{27}$ The diagnosis was, at that time, pneumonia, as in most similar cases in high altitude expeditions until the 1970s. However, Egli-Sinclair established a clear relation between these observations and altitude sickness. Can it be considered as the first description of a link between lung disease at high altitude and mountain sickness?: "Is Dr Jacottet's death not caused by the same disease [AMS]? It is my opinion. ... The rapid evolution of the lung inflammation can only be explained by the influence of 
mountain sickness on the weakening of the heart and on the energy of the nervous system of this young man, formerly so robust". ${ }^{27}$

In 1913 Ravenhill, a medical officer in a mining company in Chile, described a "puna" (AMS) of "the cardiac type", with dyspnoea, rales and cyanosis, which he defined as an acute heart condition coming on in a perfectly healthy man and disappearing rapidly with descent. ${ }^{28}$

Animal studies have been conducted since 1925 to understand better the effect of hypoxia on the lung morphology and function. Oedema, more often interstitial than clearly alveolar, has been reported by several authors, but the mechanisms of its formation are not known. ${ }^{29-32}$

A case of pulmonary oedema was described by Hurtado in 1937 but the patient probably had pre-existing cardiac disease since signs of "circulatory insufficiency" (peripheral oedema, dyspnoea, congestion of lung bases) were still present long after his acute episode had subsided. ${ }^{33}$

If we defined HAPE as a pulmonary oedema occurring at high altitude in a subject where signs of pneunomia and cardiac failure have been discarded, then the first clear description of this syndrome appeared in the 1950s and was published in Spanish in Peruvian publications. Seven cases were described between 1950 and 1952 in La Oroya $(3750 \mathrm{~m})^{3435}$ and seven between 1953 and 1954 in Morococha $(4500 \mathrm{~m})^{36}$ in residents of high altitude returning after a stay at sea level. No explanation was suggested, except that, in most cases, no clinical, radiological or electrocardiographic signs of cardiac failure were observed. In 1957 an extensive paper published by Bardalez described HAPE as a well defined nosological entity and precise hypotheses for its physiopathology were suggested. ${ }^{37}$ In 1960-1 three publications in English provided worldwide dissemination of the information to the medical public. ${ }^{63839}$ Houston described the case of a 21 year old cross country skier at $12000 \mathrm{ft}$ in Colorado. Dr P D White, a distinguished cardiologist, advised him that elevation of the pulmonary artery pressure might play a part in the pathophysiology of HAPE, with the contribution of cold and exercise (Houston, personal communication). This was confirmed in the following years by catheterisation studies which also showed normal wedge pressures; cardiac failure is not a possible causative factor of HAPE. ${ }^{2040-42}$ From the mid 1960s extensive research has been performed in hypobaric chambers, field expeditions, and by normobaric hypoxia with hypoxic gas mixtures. Many publications have come from Peru, India, North America and Europe, providing new insights into the anatomopathology, haemodynamics, pathogenesis, and treatment of HAPE. The information has spread into the climbing community, thanks to "climbing physicians" such as Charles Houston who climbed on Nanda Devi in 1936 and K2 in 1938 and dedicated a great part of his life to the research and prevention of HAPE. ${ }^{33}$ However, in spite of the comprehensive scientific data available, erroneous diagnoses are still made and pneumonia or cardiac failure are sometimes diagnosed in cases of respiratory failure occurring at high altitude. HAPE is often overlooked or mistaken for other illnesses.

\section{Is there a common pathogenesis and an individual} susceptibility in all altitude-related diseases?

The frequent association of HAPE with high altitude cerebral oedema (HACE), papilloedema, albuminuria, or peripheral oedema suggests a common pathogenesis in which a bodywide increase in capillary permeability plays a central part. ${ }^{44-46}$ The oedema is common, and the combination of high pressure and high flow in the brain could be responsible for AMS. ${ }^{47}$ The combination of hypoxia and overperfusion are necessary to produce pulmonary oedema in dogs. ${ }^{48}$ In fact, systemic hypertension is not associated with HACE or AMS, whereas pulmonary hypertension, when observed before treatment in the acute phase of the disease, is always present in HAPE. Inversely, HAPE is not always preceded by clinical signs of AMS. Severe cases of AMS with peripheral, pulmonary, and cerebral oedema have been associated with hypoventilation, weight gain and decreased urine output, suggesting a common pathogenesis involving fluid retention. ${ }^{4549}$ Thus "high altitude (HA) illness" has been suggested to be a general problem of water handling leading to water retention and transfer of fluid from intravascular to interstitial and intracellular compartments. The "high-pressure high-flow" hypothesis is advocated: systemic hypertension and cerebral vasodilation induce HACE, pulmonary hypertension and high cardiac output induce HAPE, and cutaneous vasodilation and systemic hypertension induce peripheral oedema. However, four facts go against this hypothesis: (1) cerebral oedema can appear without exercise - that is, without systemic hypertension; (2) pulmonary oedema can occur without high flow - that is, without exercise; (3) there is no cutaneous vasodilation at high altitude; and (4) severe normoxic exercise is associated with high pressure and high flow and does not produce pulmonary or cerebral oedema, even if exercise-induced arterial hypoxaemia occurs in healthy subjects at sea level..$^{50}$ There are anecdotal reports of pulmonary oedema in marathon runners but these are associated with water intoxication. However, peripheral oedema has also been found to occur with prolonged exercise at low altitude. ${ }^{51}$

Experimental evidence of hypoxia-induced increase in capillary permeability was first shown by Landis in $1932 .{ }^{52}$ Thereafter, studies gave conflicting results. Some authors showed experimental evidence of increased lung vascular permeability, ${ }^{4853-59}$ while others failed to show any increase in vascular permeability or oedema formation in the lung. ${ }^{60-65}$ Increased transvascular clearance of radiolabelled albumin was found in humans at high altitude, associated with proteinuria, ${ }^{66}$ which suggests a general increased permeability. ${ }^{67}$ The contradictions observed may be due to species differences, experimental design, or sensitivity of the method used. Pigs and rats seem more sensitive to pulmonary oedema than sheep or dogs. ${ }^{68}$ However, Viswanathan found a similar incidence of HAPE in dogs and rats and a higher incidence in mice. ${ }^{69}$ Experimental design seems to be important, particularly the duration and intensity of hypoxia and the speed of ascent. In studies where exposure to hypoxia is short (a few minutes or hours) the animals are less likely to show pulmonary oedema. ${ }^{64}$ When exposure to hypobaric pressures is very abrupt, mechanical injuries are more likely to occur. ${ }^{62}$ With a longer duration of exposure of 24-48 hours animals are more likely to mimic humans exposed to high altitude and to develop pulmonary oedema. ${ }^{59}$ The sensitivity and specificity of the techniques used to evaluate the vascular leak can also be important. Some methods specifically explore vascular permeability ${ }^{59}$ while others give indirect indices of vascular leak such as lung water or lymph flow, ${ }^{63}$ and some explore both endothelial and epithelial resistance to fluid flux. ${ }^{61}$

A low ventilatory response to hypoxia has been related to susceptibility to AMS or HAPE. Cases of HAPE have been associated with blunted or absent ventilatory responses to hypoxia or $\mathrm{CO}_{2}{ }^{70-72}$ When groups of subjects with a history of HAPE were compared with normal subjects a lower mean hypoxic ventilatory response (HVR) was found in the susceptible subjects; however, a few subjects had values in the normal range. ${ }^{734}$ When the literature on the association between HVR and AMS or HAPE is reviewed, $77 \%$ of susceptible subjects $(n=43)$ 
are found to have a low HVR and $75 \%$ of non-susceptible subjects $(n=48)$ to have a normal HVR. Thus, a low HVR is not a condition for the development of altitude sickness. ${ }^{74}$ However, better prediction can be obtained when exercise is superimposed on hypoxia during the test. ${ }^{75}$ A low HVR also has a permissive rather than a direct causative role by inducing episodes of extreme hypoxaemia during sleep. ${ }^{76}$ A high HVR seems to be protective. ${ }^{5}$ The pulmonary vascular response to hypoxia is exacerbated in subjects susceptible to HAPE. They show a more significant increase in pulmonary arterial pressure (PAP) during breathing of low oxygen concentrations, but this response to hypoxia is not found in all subjects suffering from HAPE. ${ }^{77-81}$

Thus, a low HVR would render subjects more hypoxaemic and more susceptible to high altitude diseases in general; the association with a brisk pulmonary vascular response to hypoxia could make them more susceptible to HAPE in particular. An individual susceptibility of the endothelium to a hypoxia-induced increase in permeability remains to be explored.

\section{Pathophysiology of HAPE (figure)}

Diagnoses of heart failure or pulmonary infection were rapidly discarded when the early haemodynamic studies showed pulmonary hypertension with normal or low wedge pressures, the absence of clinical signs of heart failure, and the rapid reversibility of clinical and radiological signs when oxygen availability was restored. Thus, increased PAP was considered to be the main feature in the pathogenesis of HAPE. ${ }^{3878}$ To explain alveolar oedema in the presence of precapillary vasoconstriction necessitated further assumptions. Pulmonary venous constriction ${ }^{4082}$ and transarterial leakage ${ }^{55}$ were proposed but were not confirmed experimentally. Alterations in coagulation were favoured by some authors in view of necropsy findings ${ }^{8384}$ and modifications of coagulation factors. ${ }^{8586}$ However, it is

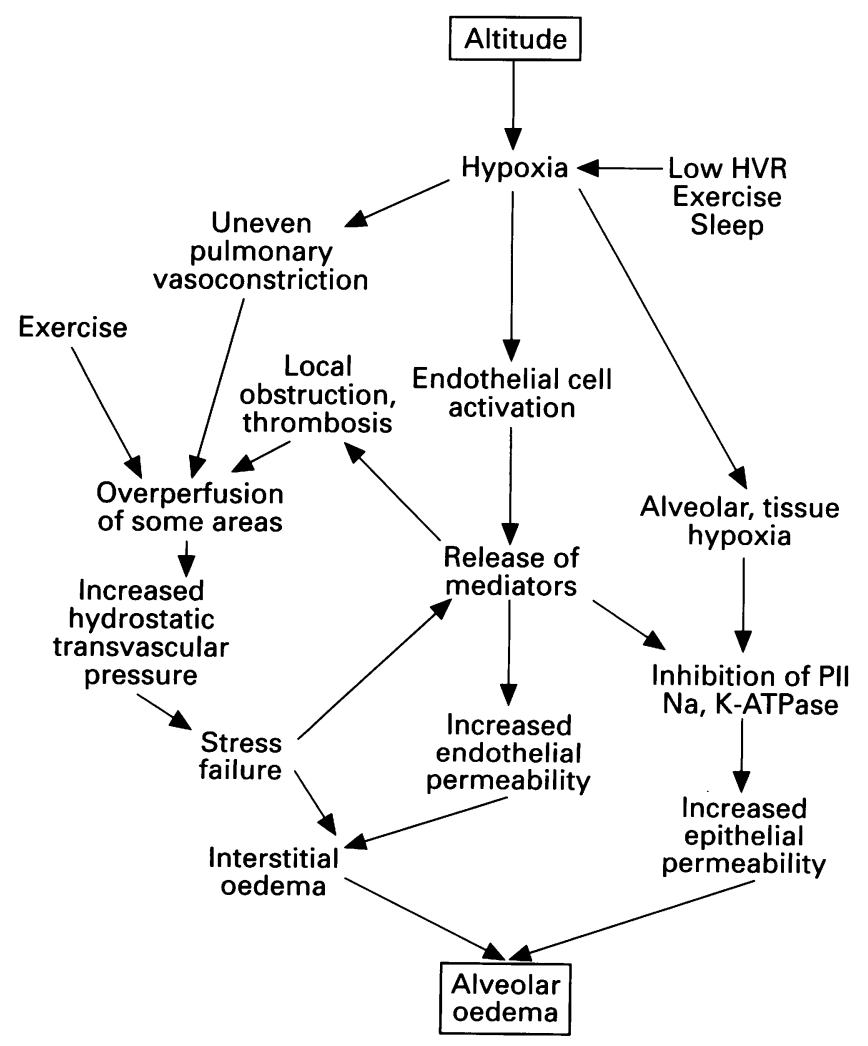

Pathophysiology of high altitude pulmonary oedema. not clear whether these alterations are the cause or the consequence of HAPE. ${ }^{87}$ The concept of "overperfusion" of unobstructed or unprotected areas of the lung was developed in the 1970 s by Hultgren and coworkers. ${ }^{5678}$ In the overperfusion concept the primary cause of HAPE would be a non-homogeneous vasoconstriction or thrombosis leading to the transmission of high blood flow and pressure to capillaries not protected by vasoconstriction. Arguments in favour of this hypothesis are: increased PAP, presence of thrombosis at necropsy, presence of oedema when blood flow is much increased in a region of the lung (pulmonary embolism, congenital absence of right pulmonary artery, ${ }^{88}$ experimental occlusion of lobar artery ${ }^{56}$ ), radiographic patchy distribution, and inhomogeneity of hypoxic vasoconstriction. ${ }^{89}$ However, hydrostatic pressures in leaking capillaries have never been measured, patchy distribution of radiographic images are transitory and non-specific for this type of pulmonary oedema, ${ }^{90}$ and coagulation disorders probably do not precede HAPE. ${ }^{87}$ When breathing hypoxic mixtures, the PAP of HAPEsusceptible subjects is not always increased above that of normal subjects. ${ }^{781}$ In contrast, very high values of PAP have been found at high altitude in exercising subjects without HAPE. ${ }^{91}$ Moreover, physiological situations where PAP is much increased (such as severe exercise in normoxia) are not associated with HAPE. Thus, an increase in PAP is probably necessary but not sufficient to induce HAPE. The concept of uneven vasoconstriction is questioned by the findings of Vock et al concerning the evolution of radiographic images from "patchy" to "homogeneous" and clinical findings suggesting that structural abnormalities are not involved in the pathogenesis. ${ }^{7}$ However, this concept was recently supported by the studies of West and coworkers who showed that a hydrostatic stress, possibly comparable to that evaluated in HAPE, could break the lung endothelium and epithelium barrier in a model of an isolated rabbit lung. ${ }^{9293}$ These alterations are less marked after reoxygenation. ${ }^{94}$ The disruption of the endothelium would expose the basal membrane and activate the release of inflammatory mediators such as thromboxane $\mathrm{B}_{2} .{ }^{95}$ This "mechanistic view" or "stress failure" hypothesis of HAPE is comparable with other diseases or manifestations such as Goodpasture's syndrome with alteration of basal membrane, haemorrhages in race horses, and disorders in mechanically hyperventilated patients. ${ }^{96}$ The mechanical damage is the primary cause, after which permeability is increased by the release of mediators.

As the concepts of the physiopathology of HAPE have developed, another aspect has expanded in parallel which suggests that the primary insult is the alteration of the endothelium, either by a direct effect of hypoxia or by the release of mediators acting on inflammation processes, vascular permeability, and vasomotor responses. In favour of this "cellular view" or "high permeability" hypothesis are the many experimental studies that show a hypoxiainduced increase in peripheral or pulmonary vascular permeability, the frequent association with oedema in other organs with the absence of systemic hypertension, the composition of alveolar fluid with a high protein content and mediators of inflammation, the frequent occurrence of HAPE at rest and often during sleep, the rapid reversibility of $\mathrm{HAPE}$ when oxygen availability is rapidly restored, and the common finding of interstitial oedema and altered oxygen transfer in the lung of normal subjects at high altitude. However, as already mentioned, some studies have failed to show any hypoxia-induced increase in capillary permeability, and the composition of alveolar fluid is also compatible with the "stress failure" hypothesis, leading to a leakage of fluid and proteins into the interstitium. The fibrin-rich alveolar oedema found at nec- 
ropsy supports the hypothesis of capillary damage ${ }^{83}$ or increased capillary permeability. ${ }^{97}$ Subclinical interstitial pulmonary oedema is a common finding in newcomers to high altitude, without HAPE..$^{869-100}$ In 1978 Staub hypothesised that shear stress-induced alteration of endothelium leads to a leakage of fluid into the interstitium. ${ }^{101}$

The effects of hypoxia on the endothelial cell permeability was investigated by Ogawa et al. ${ }^{102}$ Cultured bovine endothelium in monolayers were exposed to a $\mathrm{Po}_{2}$ of about $2 \mathrm{kPa}$. The permeability to macromolecules was increased in a time-dependent and dose-dependent manner. A significant increase was shown after $24-48$ hours with a maximum at 72 hours. It was reversible within 48 hours of reoxygenation. These changes were associated with morphological alterations - namely, larger cells and the presence of intercellular gaps. Thrombomodulin activity (a cell surface anticoagulant cofactor) was inhibited by hypoxia and reversed by reoxygenation.

The effects of hypoxia on pulmonary vascular leakage was investigated in rats by Stelzner et al. ${ }^{59}$ Rats were exposed for 1-48 hours at $60 \mathrm{kPa}$. The authors showed an increase in transvascular protein leakage that was inhibited by glucocorticoid pretreatment, augmented by adrenalectomy, and independent of pulmonary arterial pressure. This phenomenon was not seen for short exposures (1-13 hours), was similar in normobaric or hypobaric hypoxia, and was associated with increased lung water and perivascular oedema cuffs on histological examination.

Humoral processes include the release of mediators by macrophages, neutrophils, platelets, endothelial cells or epithelial cells. However, the nature of the mediator(s) is still debated. Histamine $e^{37103}$ and bradykinin ${ }^{57}$ have been suggested. The hypothesis of a hypoxia-induced activation of phospholipase $\mathrm{A}_{2}{ }^{104}$ led to the study of metabolites of arachidonic acid as mediators of altitude oedema (leukotrienes, prostaglandins, thromboxane). Some were increased in the alveolar fluid of HAPE subjects, ${ }^{910}$ in a model of mechanical lung injury, ${ }^{95}$ and in plasma at high altitude. ${ }^{105}$ Release of atrial natriuretic peptide at high altitude is controversial. It could be released in response to increased pulmonary arterial or right atrial pressures ${ }^{106-108}$ and induce an increase in capillary permeability. ${ }^{109}$ Oxygen radicals can induce vascular injury after reoxygenation and may be involved in hypoxia-induced lipid peroxidation in rat lungs. ${ }^{110}$ Cytokines (TNF, IL-1, IL-6) and nitric oxide (NO) may also have a role but their specific action on capillary permeability remains to be established. Adhesion molecules present on the surface of endothelial cells and neutrophils have recently been shown to participate in the inflammatory process. ${ }^{111}$ Endothelial leucocyte adhesion molecule 1 (ELAM-1), intercellular adhesion molecule 1 (ICAM-1), and vascular cell adhesion molecule 1 (VCAM-1) are some of the molecules that can be found in plasma and serve as markers of endothelium or neutrophil activation. Mediators such as thrombin, histamine, and cytokines (TNF, IL-1) can activate the expression of adhesion molecules via a de novo protein synthesis. Lung vascular injury could be prevented by pretreatment with anti-adhesion molecule substances. Both experimental and human studies have shown a hypoxia-induced increase in plasma endothelin levels. In a study of 10 subjects plasma levels of endothelin were increased by $51 \%$ after one week of exposure to $6542 \mathrm{~m}$. By contrast, moderate or severe exercise failed to stimulate endothelin release and the exercise-induced increase in plasma renin activity was inversely related to plasma endothelin levels. ${ }^{112113}$ In a study at the Observatoire Vallot endothelin levels increased by $82 \%$ after five days at $4350 \mathrm{~m}$; in addition, plasma levels of ELAM-1, but not ICAM-1, were also increased. ${ }^{113}$
A third hypothesis was developed in the 1970s, by analogy with traumatic neurogenic pulmonary oedema. ${ }^{114}$ A sudden discharge in the adrenergic system would lead to pulmonary oedema, either by pulmonary venous constriction or left heart failure due to systemic hypertension. Neurogenic pulmonary oedema could also be directly mediated by a permeability defect. ${ }^{115}$ The only positive argument in favour of this theory is the beneficial effect of $\alpha$ blockers in HAPE subjects. ${ }^{116}$

The conclusion drawn by Oelz et al in 1989 for the pathophysiology of HAPE is "permeability oedema in which hypoxic pulmonary hypertension is a crucial factor by enhancing the flow of liquid across the damaged endothelial barrier". ${ }^{117}$

\section{HAPE: vascular or epithelial leak?}

It is important to consider that vascular permeability to fluid is a normal physiological process described by Starling's equation. ${ }^{101}$ Moreover, many individuals develop pulmonary interstitial oedema or subcutaneous oedema at high altitude without HAPE. Fishman stressed the role of the alveolar rather than the endothelial barrier, and the role of lymphatic drainage in limiting interstitial oedema. ${ }^{118}$ Pulmonary interstitial oedema occurs with a small increase in vascular hydrostatic pressure. Compliance of lung vessels and interstitium is high, and only a 5-8\% increase in lung weight is associated with peribronchovascular oedema. As much as a $35 \%$ increase in lung weight is necessary for alveolar oedema. Epithelial permeability is 10 times less than endothelial permeability which makes the epithelium a much stronger barrier than the endothelium. The question arises, however, whether the alveolar epithelium rather than the capillary endothelium is the limiting factor in the development of alveolar oedema.

Recent studies indicate that certain pneumocyte functions may be altered in hypoxia. ${ }^{119120}$ Sodium transport by the alveolar epithelium represents an important mechanism for clearance of airspace fluid in acute lung injury. We have examined whether hypoxia affects $\mathrm{Na}, \mathrm{K}$-ATPase activity in alveolar epithelial cells. SV40 virus transformed rat type II alveolar epithelial cells were exposed to either hypoxia $\left(5 \% \mathrm{O}_{2}\right)$ or normoxia $\left(21 \% \mathrm{O}_{2}\right)$ for increasing durations (up to 48 hours) in the absence or presence of $10^{-5} \mathrm{M}$ nifedipine. Na,K-ATPase activity was determined using ouabain-sensitive rubidium-86 influx (OsRb). Exposure to hypoxia for at least 12 hours induced a time-dependent decrease in OsRb. Incubation of normoxic cells with supernatant of hypoxic cells resulted in a $45 \%$ decrease of OsRb within one hour. ${ }^{119}$ Nifedipine prevented the hypoxiainduced decrease in OsRb. ${ }^{120}$ These results indicate that: (1) hypoxia induces a time-dependent decrease of $\mathrm{Na}, \mathrm{K}$ ATPase activity in alveolar type II cells; (2) this effect is most likely to be due to the release of a soluble factor; and (3) it is prevented by nifedipine. Autocrine alteration of the $\mathrm{Na}, \mathrm{K}$-ATPase activity in alveolar epithelial cells during hypoxia may reduce clearance of airspace fluid and contribute to the formation and/or maintenance of alveolar oedema.

\section{Treatment of HAPE}

The complexity of the physiopathology is in sharp contrast to the simplicity of treatment and evolution of the disease. ${ }^{121}$ Very few controlled studies have been conducted on the treatment of HAPE for obvious practical ethical reasons. The main treatment is to restore oxygen availability, either naturally by descending, or by inhaling oxygen or recompression in a portable hyperbaric chamber. Portable hyperbaric chambers have led to new practical possibilities for field care of HAPE. ${ }^{122}$ However, hyperbaric treatment 
has a short beneficial effect on AMS but no controlled evaluation has been performed in patients with HAPE. ${ }^{123}$ It should not delay descent, which is the most efficient way to treat patients with HAPE.

The use of frusemide, first advocated by Indian authors, ${ }^{19}$ was rapidly abandoned because of lack of efficiency and the pathophysiological characteristics of HAPE. Blood volume and blood flow are already low, there is no left ventricular failure, and the risk of hypovolaemia and hypotension is high. Morphine has frequently been used in the field ${ }^{5}$ but without controlled studies, and it is generally discarded because of its depressant effect on ventilation. Dexamethasone has been used but no controlled studies of its use in HAPE have been performed. The efficiency of acetazolamide, well established for AMS, is debatable for HAPE. Antibiotics are recommended because infection may develop in the waterlogged lung. ${ }^{3}$ Refractoriness to administration of $100 \%$ oxygen is rare in HAPE; however, in some cases the development of severe prolonged acute respiratory failure may initiate a state similar to the adult respiratory distress syndrome (ARDS). ${ }^{124}$

The idea of using nifedipine in HAPE came from the effect of calcium antagonists on pulmonary hypertension in rats. ${ }^{125}$ In 1987 Oelz reported his own case of HAPE which occurred at $6900 \mathrm{~m}$. He used nifedipine $20 \mathrm{mg}$ sublingually first, followed by $20 \mathrm{mg}$ slow release nifedipine. This allowed him to descend to $5400 \mathrm{~m}$. Another episode of HAPE the following night was treated the same way and resolved, allowing a further descent to $4000 \mathrm{~m}$ the next morning. Obviously the nifedipine helped, but the descent itself may have played a part. ${ }^{126}$ Nifedipine was given $(20 \mathrm{mg}$ sublingually followed by $20 \mathrm{mg}$ slow release every six hours) to six subjects with HAPE at $4559 \mathrm{~m}$. Clinical improvement, increased $\mathrm{PaO}_{2}$, decreased (A-a) $\mathrm{Do}_{2}$, decreased PAP (echo Doppler), and progressive clearing of oedema (radiography) was observed without side effects except persistent headache in four subjects. The decrease in PAP was probably responsible for the therapeutic effects, although other pharmacological effects of nifedipine cannot be ruled out. ${ }^{117}$ For example, nifedipine could also act in blocking the inflammatory response to hypoxia or pneumocyte reabsorptive function. ${ }^{120}$ The general use of nifedipine in HAPE-susceptible subjects should not be encouraged at present as it has potentially harmful side effects; however, it offers a potential emergency measure for patients when descent or evacuation is impossible. ${ }^{117}$ The prophylactic administration of nifedipine ( $20 \mathrm{mg}$ slow release every six hours) is effective in lowering PAP and preventing HAPE in susceptible subjects. ${ }^{127}$ In 14 mountaineers ascending to $4559 \mathrm{~m}$, with or without AMS but no HAPE, nifedipine decreased PAP and slightly decreased systemic arterial pressure, but had no effect on $\mathrm{PaO}_{2}$ and AMS; thus, nifedipine or isradipine cannot be recommended for prevention of benign AMS. ${ }^{128129}$

The rationale for the use of $\alpha$ blockers is based on neurogenic pulmonary oedema with massive adrenergic discharge. It was shown to be efficient in field situations, with or without oxygen. ${ }^{116}$

Prevention depends on slow ascent for progressive acclimatisation, rest after ascent, clinical education, and early recognition of symptoms. The detection of HAPEsusceptible subjects with appropriate hypoxic tests should be encouraged. ${ }^{75}$

Inhaled nitric oxide (NO) has recently been used to treat HAPE at $4559 \mathrm{~m} .{ }^{130}$ Its vasorelaxant action on the pulmonary vasculature, associated with its rapid inactivation within the circulation by haemoglobin which prevents any peripheral action, are interesting features. However, it is not yet of practical use in the field.

\section{New developments}

There are two main barriers to a better understanding of HAPE: (1) the lack of a good animal model of hypoxiainduced alveolar oedema, and (2) the difficulty of performing controlled studies in patients suffering from HAPE in remote areas, far from hospital facilities. Non-invasive studies of the pulmonary circulation could help us to understand the time dependence of pulmonary hypertension with the appearance of HAPE. Is alveolar oedema the cause or the consequence of pulmonary hypertension? Molecular biology could also help by providing information about the eventual role of hypoxic sensing dysfunction. Hypoxic sensing can be seen in chemoreceptors, in EPOproducing cells, and in vessels producing vasoconstriction in the lungs and vasodilation in the periphery. ${ }^{131}$ Hypoxia is most probably sensed at the molecular level and upregulates the expression of several genes, especially coding for EPO, endothelin, or vascular endothelial growth factor (also known as vascular permeability factor). ${ }^{131}$ Studies on these molecular mechanisms may provide further insight into the pathophysiology of HAPE and in the susceptibility of individuals to develop the condition.

In-breeding studies in cattle have shown that the responsiveness of the pulmonary circulation to hypoxia is genetically coded. ${ }^{132}$ Anecdotal reports of a familial predisposition to $\mathrm{HAPE}^{6142840}$ need further investigations in humans. Genetic characteristics of HAPE could be explored with new generations of young alpinists.

\section{Conclusions}

The hypoxic challenge triggers important changes in both the pulmonary and the peripheral circulation systems. Increased interstitial or tissue oedema is the main feature of altitude-induced hypoxia. An exacerbation of the permeability properties of the endothelium could be directly mediated by hypoxia or by substances released locally. In the pulmonary circulation hypoxic arteriolar vasoconstriction and pulmonary hypertension interfere with the increased vascular permeability. Interstitial oedema has only limited functional consequences, but when oedema develops within the alveoli or the brain severe consequences may result. The precise mechanisms by which lung interstitial oedema turns into alveolar oedema remain to be elucidated by further studies on epithelial function. ${ }^{133}$ Individual susceptibility to the condition also deserves further investigation so that better means of prevention and treatment can be developed.

ARPE,

J-P RICHALET

Laboratoire de Physiologie,

UFR de Médecine,

93012 Bobigny

France

1 Hackett PH, Rennie ID, Levine HD. The incidence, importance, and prophylaxis of acute mountain sickness. Lancet 1976;ii:1149-54. prophylaxis of acute mountain sickness. Lancet 1976;ii:1149-54.

3 Houston CS. Altitude illness. Emerg Med Clin North Am 1984;2:503-12. Schoene RB. Pulmonary edema at high altitude: review, pathophysiology and update. Clin Chest Med 1985;6:491-507.

5 Hackett PH, Roach RC. High altitude pulmonary edema. $f$ Wilderness Med 1990;1:3-26.

6 Hultgren HN, Spickard WB, Hellriegel K, Houston CS. High altitude pulmonary edema. Medicine 1961;40:289-313.

7 Vock P, Brutsche MH, Nanzer A, Bärtsch P. Variable radiomorphologic data of high altitude pulmonary edema. Chest 1991;100:1306-11.

8 Maldonado D. High altitude pulmonary edema. Radiol Clin North Am 1978;16:537-49.

9 Schoene RB, Hackett PH, Henderson WR, Sage EH, Chou M, Roach $\mathrm{RC}$, et al. High altitude pulmonary edema. Characteristics of lung lavage

10 Schoene RB, Swenson ER, Pizzo CJ, Hackett PH, Roach RC, Mills Jr $\mathrm{WJ}$, et al. The lung at high altitude: bronchoalveolar lavage in acute mountain sickness and pulmonary edema. F Appl Physiol 1988;64:260513.

11 Houston CS, Dickinson JG. Cerebral form of high altitude illness. Lancet 1975;ii:758-61. 
12 Menon ND. High altitude pulmonary edema. N Engl f Med 1965;273: $66-73$

13 Lobenhoffer HP, Zink RA, Brendel W. High altitude pulmonary edema: analysis of 166 cases. In: Brendel W, Zink RA, eds. High altitude physiology and medicine. New York: Springer-Verlag, 1982:219-31.

14 Scoggin $\mathrm{CH}$, Hyers TM, Reeves JT, Grover RF. High altitude pulmonary edema in the children and young adults of Leadville, Colorado. $N$ Eng f Med 1977;297:1269-72.

15 Hultren HN, Marticorena E. High altitude pulmonary edema: epidemiologic observations in Peru. Chest 1978;74:372-6.

16 Richalet JP. Le mal des montagnes frappe les Alpes. La Recherche 1990; 223:928-9.

17 Maggiorini M, Bühler B, Walter M, Oelz O. Prevalence of acute mountain sickness in the Swiss Alps. BMF 1990;301:853-5.

18 Sophocles AM. High-altitude pulmonary edema in Vail, Colorado, 19751982. West $\mathcal{F}$ Med 1986;144:569-73.

19 Singh I, Kapila CC, Khanna PK, Nanda RB, Rao BD. High altitude pulmonary oedema. Lancet 1965; i:229-34.

20 Roy SB, Guleria JS, Khanna PK, Manchanda SC, Pande JN, Subba PS. Haemodynamic studies in high altitude pulmonary oedema. Br Heart $\mathcal{f}$ 1969;31:52-8.

21 Viswanathan R, Jain SK, Subramanian S. Pulmonary edema of high altitude III. Pathogenesis. Am Rev Respir Dis 1969;100:342-9.

22 Gilbert DL. The first documented report of mountain sickness: the China or headache story. Respir Physiol 1983;52:315-26.

23 Acosta de J. Historia natural y moral de las Indias. Seville, 1590.

24 Bert P. La pression barométrique. Paris: Masson, 1878

25 Vallot J. Difficultés des observations scientifiques aux grandes altitudes. Ann Obs Mont Blanc 1896;2:165-88.

26 Mosso A. Fisiologia dell'Uomo sulle Alpi. Milan: Fratelli Treves, 1897.

27 Egli-Sinclair. Sur le mal de montange. Ann Obs Mont Blanc 1893;1:107-30.

28 Ravenhill TH. Some experiences of mountain sickness in the Andes. Trop Med Hyg 1913;1620:313-20.

29 Bayeux R. Modifications structurales du poumon sous l'influence des grandes décompressions barométriques. C R Acad Sci 1925;180:1701-3.

30 Piéry M, Martin J-F, Enselme J, Peschiera C. Etude expérimentale de l'influence biologique d'un séjour prolongé à l'altitude. Les modifications pulmonaires. CR Acad Sci 1939;208:1367-8.

31 Campbell JA. Living at very high altitudes and maintenance of normal health. Lancet 1930;370-3.

32 Mori Chavez P. Contribucion al estudio del soroche experimental. Manifestaciones pulmonares del cuy en el soroche agudo. Anal Fac Med (Lima) $1935 ; 126-72$

33 Hurtado A. Aspectos fisiologicos y patologicos de la vida en las Alturas. Lima Imprenta Rimac, 1937.

34 Lundberg EA. Edema agudo del pulmon, en el soroche. Conferencia de la Asociacion Medica de Yauli, La Oroya, 1952.

35 Lizarraga L. Edema agudo de pulmon. Anal Fac Med (Lima) 1955;36: 244.

36 Bardalez AV. Algunos casos de edema pulmonar agudo por soroche grave. Anal Fac Med (Lima) 1955;33:232-43.

37 Bardalez AV. Edema pulmonar agudo por soroche grave. Asoc Med Yauli 1957;2:279-305.

38 Houston CS. Acute pulmonary edema of high altitude. $N$ Engl f Med 1960;263:478-80.

39 Alzamora-Castro V, Garrido-Lecca G, Battilana G. Pulmonary edema of high altitude. Am $\mathcal{f}$ Cardiol 1961;7:769-78.

40 Fred HL, Schmidt AM, Bates T, Hecht HH. Acute pulmonary edema a altitude. Clinical and psychological observations. Circulation 1962;25 929-37

41 Hultgren HN, Lopez CE, Lundberg E, Miller H. Physiologic studies of pulmonary edema at high altitude. Circulation 1964;29:393-408.

42 Marticorena E, Tapia FA, Dyer J, Severino J, Banchero N, Gamboa R, al. Pulmonary edema by ascending to high altitudes. 7 Dis Chest 1964 45:273-83.

43 Sutton JR, Lassen NA. Pathophysiology of acute mountain sickness and high altitude pulmonary edema: an hypothesis. Bull Eur Physiopatho Respir 1979;15:1045-52.

44 Hackett PH, Rennie ID. Rales, peripheral edema, retinal hemorrhage and acute mountain sickness. Am f Med 1979;67:214-8.

45 Hackett PH, Rennie ID, Grover RF, Reeves JT. Acute mountain sickness and the edemas of high altitude: a common pathogenesis? Respir Physio 1981;46:383-90

46 Kobayashi T, Koyama S, Kubo K, Fukushima M, Kusama S. Clinical features of patients with high altitude pulmonary edema in Japan. Chest 1987;92:814-21.

47 Sutton JR, Houston CS. In: Sutton JR, Coates G, Remmers JE, eds. Hypoxia. The adaptations. Toronto: Dekker, 1990:XXV-XXXII

48 Courtice FC, Korner PI. The effect of anoxia on pulmonary oedema produced by massive intravenous infusions. Austral f Exp Biol Med Sci 1952;30:511-26.

49 Hackett PH, Rennie ID, Hofmeister SE, Grover RF, Grover EB, Reeves JT Fluid retention and relative hypoventilation in acute mountain sickness Repiration 1982;43:321-9.

50 Sheridan JW, Sheridan R. Tropical high-altitude peripheral œdema. Lancet 1970;i:242.

51 Dempsey JA, Hanson PG, Henderson KS. Exercise-induced arterial hypoxemia in healthy human subjects at sea level. $\mathcal{f}$ Physiol 1984;355. poxemia

52 Landis EM, Jonas L, Angevine M. Erb W. The passage of fluid and protein through the human capillary wall during venous congestion. $\mathcal{F}$ Clin Invest 1932;11:17-29.

53 Maurer FW. The effect of decreased blood oxygen and increased blood carbon dioxide on the flow and composition of cervical and cardiac lymph. Am 7 Physiol 1940;131:331-48.

54 Warren MF, Drinker CK. The flow of lymph from the lungs of the dog Am f Physiol 1942;136:207-21.

55 Whayne TF, Severinghaus JW. Experimental hypoxic pulmonary edem in the rat. F Appl Physiol 1968;25:729-32.

56 Hultgren HN. High altitude pulmonary edema. In: Staub N, ed. Lung water and solute exchange. Vol 7, Lenfant Series, New York: Marcel Dekker, 1978:437-69.

57 O'Brodovich HM, Stalcup SA, Mei Pang L, Lipset JS, Mellins RB. Bradykinin production and increased pulmonary endothelial permeability during acute respiratory failure in unasthetized sheep. 7 Clin Invest 1981 67:514-22.

58 Mitzner W, Sylvester JT. Hypoxic vasoconstriction and fluid filtration in pig lungs. $\mathcal{f}$ Appl Physiol 1981;51:1065-71

59 Stelzner TJ, O,Brien RF, Sato K, Weil JV. Hypoxia-induced increases in pulmonary transvascular protein escape in rats. Modulation by glucocorticoids. f Clin Invest 1988;82:1840-7.

60 Hemingway A. Pulmonary edema in guinea-pigs during severe hypoxia. $f$ Appl Physiol 1952;4:868-72.

61 Mooi W, Smith P, Heath D. The ultrastructural effects of acute decompression on the lung of rats: the influence of frusemide. $\mathcal{F}$ Patho 1978;126:189-96

62 Meyrick B, Miller J, Reid L. Pulmonary oedema induced by antu, or by high or low oxygen concentrations in rat - an electron microscopic study Br f Exp Pathol 1972;53:347-58

63 Bland RD, Demling RH, Selinger SL, Staub N. Effects of alveolar hypoxia on lung fluid and protein transport in unanaesthetized sheep. Circ Res 1977;40:269-74

64 Landolt CC, Matthay MA, Albertine KH, Roos PJ, Wiener-Kronish JP, Staub NC. Overperfusion, hypoxia and increased pressure cause only hydrostatic pulmonary edema in anesthetized sheep. Circ Res 1983;52 $335-41$.

65 Homik LA, Bshouty Z, Light RB, Younes M. Effect of alveolar hypoxia on pulmonary fluid filtration in in situ dog lungs. 7 Appl Physiol 1988 $65: 46-52$

66 Hansen JM, Olsen NV, Feldt-Rasmussen B, Kanstrup I-L, Déchaux M, Dubray $\mathrm{C}$, et al. Albuminuria and overall capillary permeability of albumin in acute altitude hypoxia. F Appl Physiol 1994;76:1922-7.

67 Bradwell AR, Delamere JP. The effect of acetazolamide on the proteinuria of altitude. Aviat Space Environ Med 1982;53:40-3.

68 Schoene RB, Goldberg S. The quest for an animal model of high altitude pulmonary edema. Int $\mathcal{7}$ Sports Med 1992;13:S59-60

69 Viswanathan R, Jain SK, Subramanian S, Puri BK. Pulmonary edema of high altitude $I$. Production of pulmonary edema in animals under conditions of simulated high altitude. Am Rev Respir Dis 1969;100:327-33.

70 Kafer ER, Leigh J. Recurrent respiratory failure associated with the absence of ventilatory response to hypercapnia and hypoxemia. Am Rev Respi Dis $1972 ; 106: 100-8$

71 Lakshminarayan S, Pierson DJ. Recurrent high altitude pulmonary edema with blunted chemosensitivity. Am Rev Respir Dis 1975;111:869-72.

72 Hyers TM, Scoggin CH, Will DH, Grover RF, Reeves JT. Accentuated hypoxemia at high altitude in subjects susceptible to high-altitude pulmonary edema. $\mathcal{F}$ Appl Physiol 1979;46:41-6.

73 Matsuzawa Y, Fujimoto K, Kobayashi T, Numishi NR, Harada K, Kohno $\mathrm{H}$, et al. Blunted hypoxic ventilatory drive in subjects susceptible to highaltitude pulmonary edema. F Appl Physiol 1989;66:1152-7.

74 Selland MA, Stelzner TJ, Stevens T, Mazzeo RS, McCullough RE, Reeves JT. Pulmonary function and hypoxic ventilatory response in subject susceptible to high-altitude pulmonary edema. Chest 1993;103:111-6.

75 Richalet JP, Keromes A, Dersch B, Corizzi F, Mehdioui H, Pophillat B, et al. Caractéristiques physiologiques des alpinistes de haute altitude. Science and Sports 1988;3:89-108.

76 Hackett PH, Roach RC, Schoene RB, Harrison GL, Mills Jr WJ. Abnorma control of ventilation in high-altitude pulmonary edema. $7 \mathrm{Appl}$ Physiol 1988;64:1268-72.

77 Penaloza D, Sime F. Circulatory dynamics during high altitude pulmonary edema. Am f Cardiol 1969;23:369-78.

78 Hultgren HN, Grover RF, Hartley LH. Abnormal circulatory response to high altitude in subjects with a previous history of high altitude pulmonary edema. Circulation 1971;44:759-70.

79 Viswanathan R, Jain SK, Subramanian S, Subramanian TA, Dua GL, Gir J. Pulmonary edema of high altitude II. Clinical, aerohemodynamic, and biochemical studies in a group with history of pulmonary edema of high altitude. Am Rev Respir Dis 1969;100:334-41.

80 Viswanathan R, Subramanian S, Lodi ST, Radha TG. Further studies on pulmonary oedema of high altitude. Respiration 1978;36:216-22.

81 Naeije R, Melot C, Lejeune P. Hypoxic pulmonary vasoconstriction and high altitude pulmonary edema. Am Rev Respir Dis 1986;134:332-3.

82 Hyman AL. Effects of large increases in pulmonary blood flow on pulmonary venous pressure. F Appl Physiol 1969;27:179-85.

83 Nayak NC, Roy S, Narayaran TK. Pathologic features of altitude sickness. Am 7 Pathol 1964;45:381-91.

84 Dickinson JG, Heath J, Gosney J, Williams D. Altitude related deaths in seven trekkers in the Himalayas. Thorax 1983;38:646-56.

85 Singh I, Chohan IS. Adverse changes in fibrinolysis, blood coagulation and platelet function in high altitude pulmonary oedema. Int 7 Biometeo 1974;18:33-45.

86 Grav GW, McFadden MD, Houston CS, Bryan AC. Changes in the single-breath nitrogen washout curve on exposure to $17600 \mathrm{ft}$. $\mathcal{F} A p p$ Physiol 1975;39:652-6.

87 Bärtsch P, Waber UR, Haeberli A, Maggiorini M, Kriemler S, Oelz O, er al. Enhanced fibrin formation in high-altitude pulmonary edema. 7 App Physiol 1987;63:752-7.

88 Hackett PH, Creagh CE, Grover RF, Honigman B, Houston CS. High altitude pulmonary edema in per

N Engl $\ngtr$ Med 1980;302:1070-3.

89 Lehr DFE, Tuller MA, Fisher LC, Ellis K, Fishman AP. Induced changes in the pattern of pulmonary blood flow in the rabbit. Circ Res 1963;13 $119-31$

90 Milne ENC, Pistolesi M, Miniati M, Giuntini C. The radiologic distinction of cardiogenic and noncardiogenic edema. $A \mathscr{F} R$ 1985;144:879-94.

91 Groves BM, Reeves JT, Sutton JR, Wagner PD, Cymerman A, Malconian MK, et al. Operation Everest II: elevated high-altitude resistance unresponsive to oxygen. $\mathcal{F}$ Appl Physiol 1987;63:521-30.

92 West JB, Tsukimoto K, Mathieu-Costello O, Prediletto R. Stress failure in pulmonary capillaries. 7 Appl Physiol 1991;70:1731-42.

93 West JB, Mathieu-Costello O. High altitude pulmonary edema is caused by stress failure of pulmonary capillaries. Int $\mathcal{f}$ Sports Med 1992;13:S54-8.

94 Elliott AR, Fu Z, Tsukimoto K, Prediletto R, Mathieu-Costello O, West JB. Short-term reversibility of ultrastructural changes in pulmonary capillarie caused by stress failure. F Appl Physiol 1992;73:1150-8.

95 Tsukimoto K, Yoshimura N, Ichioka M, Tojo N, Miyazato I, Marumo F, et al. Protein, cell and $\mathrm{LTB}_{4}$ concentrations of lung edema fluid produced by high capillary pressures in rabbit. $\mathcal{F}$ Appl Physiol 1994;76:321-7. 
96 West JB, Mathieu-Costello O. Stress failure of the pulmonary capillaries: role in lung and heart disease. Lancet 1992;340:762-7.

97 Arias-Stella J, Kryger $\mathrm{H}$. Pathology of high altitude pulmonary edema. Arch Pathol 1963;76:43-53.

98 Kronenberg RS, Safar P, Lee J, Wright F, Noble W, Wahrenbrock E, et al. Pulmonary artery pressure and alveolar gas exchange in man during acclimatization to $12470 \mathrm{ft} \mathcal{F}$ Clin Invest 1971:50:827-37.

99 Sutton JR, Bryan AC, Gray GW, Horton ES, Rebuck AS, Woodley W, et al. Pulmonary gas exchange in acute mountain sickness. Aviat Space Environ Med 1976;47:1032-7.

100 Jaeger JJ, Sylvester JT, Cymerman A, Berberich JJ, Denniston JC, Maher JT. Evidence for increased intrathoracic fluid volume in man at high altitude. $\mathcal{F}$ Appl Physiol 1979;47:670-6.

101 Staub NC. Pulmonary edema due to increased microvascular permeability to fluid and protein. Circ Res 1978;43:143-51.

102 Ogawa S, Gerlach H, Esposito C, Pasagian-Macaulay A, Brett J, Stern D. Hypoxia modulates the barrier and coagulant function of cultured D. Hypoxia modulates the barrier and coagulant
bovine endothelium. $₹$ Clin Invest 1990;85:1090-8.

103 Haas F, Bergofsky EH. Role of the mast cell in the pulmonary pressor response to hypoxia. $\mathcal{f}$ Clin Invest 1972;51:3154-62.

104 Voelkel NF. Review: species variation in the pulmonary responses to arachidonic acid metabolites. Prostaglandins 1985;29:867-89

105 Richalet J-P, Hornych A, Rathat C, Aumont J, Larmignat P, Rémy P. Plasma prostaglandins, leukotrienes and thromboxane in acute high altitude hypoxia. Respir Physiol 1991;85:205-15.

106 Bärtsch P, Shaw S, Francioli M, Gnadinger MP, Weidmann P. Atrial natriuretic peptide in acute mountain sickness. F Appl Physiol 1988;65: 1929-37.

107 Cosby RL, Sophocles AM, Durr JA, Perrinjaquet CL, Yee B, Schrier RW. Elevated plasma atrial natriuretic factor and vasopressin in high-altitude pulmonary edema. Ann Intern Med 1988;109:796-9.

108 Kawashima A, Kubo K, Matsuzawa Y, Kobayashi T, Sekiguchi M. Hypoxia-induced ANP secretion in subjects susceptible to high-altitude pulmonary edema. Respir Physiol 1992;89:309-17.

109 Weidmann P, Hasler L, Gnädinger MP, Lang RE, Uehlinger DE, Shaw $\mathrm{S}$, et al. Blood levels and renal effects of atrial natriuretic peptide in normal man. 7 Clin Invest 1986;77:734-42.

110 Torok B, Roth E, Zsoldos T, Tigyi A, Matkovic S, Szabo L. Lipid peroxidation in lung of rats exposed to hyperoxic, hypoxic and ischemic perfects. Exp Pathol 1986;29:221-6.

111 Gearing JH, Newman W. Circulatory adhesion molecules in disease. Immunol Today 1993;14:506-12.

112 Richalet J-P, Déchaux M, Bienvenu A, Cauchy E, Souberbielle J-C, Antezana AM, et al. Renal function and hormones in humans during prolonged exposure to extreme altitude hypoxia. Arch Int Physiol Biochim Biophys 1994;102:A111.

113 Déchaux M, Blazy I, Khayal S, Souberbielle J-C, Letournel M, Richalet J-P. Hypoxia-induced activation of endothelial cells. Ninth Hypoxia Symposium, Lake Louise, Canada, 1995.
114 Theodore J, Robin ED. Pathogenesis of neurogenic pulmonary oedema. Lancet 1975;7938:749-51.

115 Colice GL, Matthay MA, Bass E, Matthay RA: Neurogenic pulmonary edema. Am Rev Respir Dis 1984;130:941-8.

116 Hackett PH, Roach RC, Hartig GS, Greene ER, Levine BD. The effect of vasodilators on pulmonary hemodynamics in high altitude pulmonary edema: a comparison. Int $\mathcal{f}$ Sports Med 1992;13:S68-71.

117 Oelz O, Maggiorini M, Ritter M, Waber U, Jenni R, Vock $P$, et al. Nifedipine for high altitude pulmonary edema. Lancet 1989;ii:1241-4.

118 Fishman AP. Pulmonary edema: the water-exchanging function of the lung. Circulation 1972;46:390-408.

119 Planès C, Michaut C, Friedlander G, Amiel C, Clerici C. Hypoxia decreases $\mathrm{Na}, \mathrm{K}$-ATPase activity in rat alveolar epithelial type II cells. FASEB $₹$ 1994;A141.

120 Planès C, Richalet J-P, Friedlander G, Amiel C, Clérici C. Nifedipine prevents hypoxia-induced decrease of Na,K-ATPase activity in alveolar
type II cells. Ninth Hypoxia Symposium, Lake Louise, Canada, 1995.

121 Coudert J. High-altitude pulmonary edema. Med Sport Sci 1985;19: 90-102.

122 Taber RL. Protocols for the use of a portable hyperbaric chamber for the treatment of high altitude disorders. $\mathcal{F}$ Wilderness Med 1990;1: 181-92.

123 Bärtsch P. Treatment of high altitude diseases without drugs. Int $\mathcal{F}$ Sports Med 1992;13:S71-3.

124 Zimmerman GA, Crapo RO. Adult respiratory distress syndrome secondary to high altitude pulmonary edema. West 7 Med 1980;133:335-7.

125 Stanbrook HS, Morris KG, McMurtry IF. Prevention and reversal of hypoxic pulmonary hypertension by calcium antagonists. Am Rev Respir Dis 1984;130:81-5.

126 Oelz $\mathrm{O}$. A case of high altitude pulmonary edema treated with nifedipine (letter). $\Im A M A$ 1987;257:780.

127 Bärtsch P, Maggiorini M, Ritter M, Noyi C, Vock P, Oelz O. Prevention of high-altitude pulmonary edema by nifedipine. $N$ Engl $f$ Med 1991; 325:1284-9.

128 Hohenhaus E, Niroomand F, Goerre S, Vock P, Oelz O, Bärtsch P. Nifedipine does not prevent acute mountain sickness. Am $\mathcal{F}$ Respir Crit Care Med 1994;150:857-60.

129 Dugas L, Dubray C, Herry JP, Olsen NV, Court-Payen M, Hansen JM, et al. Effets cardiovasculaires d'un bloqueur clacique en hypoxie d'altitude. La Presse Méd 1995;24:763-8.

130 Vollenweider L, Delabays A, Kleger GR, Ballmer P, Nicod P, Bärtsch P, et al. Inhaled nitric oxide for high-altitude pulmonary edema. Ninth et al. Inhaled nitric oxide for high-altitude pulmo

131 Goldberg MA, Schneider TJ. Similarities between the oxygen-sensing mechanisms regulting the expression of susceptibility to hypoxic pulmonary hypertension. Prog Respir Res 1975;9:112-7.

133 Richalet JP. Quantification of hypoxia-induced vascular and epithelial leak. Possible mechanisms. Ninth Hypoxia Symposium, Lake Louise, Canada, 1995. 